\title{
Excessive carbohydrate consumption and body mass index: the risk factors for type 2 diabetes mellitus in patients with Prader- Willi syndrome in Tamil Nadu population
}

Padmavathi Vijayakumar ${ }^{1 *}$, Arul Narayanasamy ${ }^{2}$ and Balachandar Vellingiri ${ }^{1}$

\begin{abstract}
Background: Prader-Willi syndrome (PWS) is commonly associated with severe obesity and type 2 diabetes mellitus (T2DM) and is caused by excessive eating. Only very few studies have reported the relationship between excessive eating, weight gain, and T2DM associated with PWS. The aim of the present study was to investigate the relationship between high carbohydrate intake, body mass index (BMI), and the associated risk factor of T2DM development in people with PWS. We collected data from 23 PWS patients along with obesity control (OC) in Tamil Nadu, India. All PWS patients had T2DM whereas only 7 of 23 OC subjects had T2DM. The physical and biochemical parameters were compared in both subjects. We estimated daily intake in grams of food and calories for each item consumed by both PWS and OC subjects (with and without T2DM). Additionally, we compared BMI values and macronutrients, to investigate the occurrence of T2DM in PWS.
\end{abstract}

Results: All statistical analyses were done using mean \pm SD. PWS subjects showed BMI values that were extremely significant in both adolescent and adult ( $p$ value $<0.0001$ ) compared to OC subjects. All biochemical parameters were extremely significant in the adolescent than in the adult group of PWS compared to OC subjects. The current study showed that PWS subjects consume significantly more carbohydrates from total white rice intake and they have exceeding BMI values when compared to OC subjects with and without T2DM ( $p$ value 0.05).

Conclusion: This is the first report on excessive carbohydrate consumption of $>300 \mathrm{~g}$ by PWS patients in Tamil Nadu with $\mathrm{BMI} \geq 30 \mathrm{~kg} / \mathrm{m}^{2}$ as a risk factor for T2DM. We highly recommend the optimal daily intake of white rice to prevent the development of T2DM in PWS.

Keywords: Prader-Willi syndrome, Obesity control, T2DM, Carbohydrates, Body mass index

\section{Background}

Prader-Willi syndrome (PWS) is a complex neurogenetic disorder, which is caused by inherited deletion of paternal genes at the imprinting center (IC) on chromosome $15 \mathrm{q} 11$-q13 region. It is prevalent in about 1 in 15,000 to 20,000 people (Bittel \& Butler, 2005; Nicholls \& Knepper, 2001). The characteristics of PWS in commonly observed infants are severe feeding difficulties, hypotonia, weak cry, poor suck, and failure to thrive, followed by

\footnotetext{
* Correspondence: geneticpadmeens@yahoo.com

${ }^{1}$ Human Molecular Cytogenetics and Stem Cell Laboratory, Department of Human Genetics and Molecular Biology, Bharathiar University, Coimbatore, Tamil Nadu 641046, India

Full list of author information is available at the end of the article
}

excessive eating in early childhood and gradual development of morbid obesity due to uncontrolled eating behavior (Butler et al., 2009; McCandless et al., 2011). These PWS characteristics mainly occur due to dysfunction of three molecular genetics mechanisms, viz., 70\% de novo interstitial deletions of the chromosome 15q11q13 region, 25\% maternal uniparental disomy (matUPD), and $2-5 \%$ imprinting defect (Buiting et al., 1995). However, the exact genetic mechanism is currently unclear for the excessive eating behavior and its associated risk of morbid obesity and type 2 diabetes mellitus (T2DM) in PWS. Few studies have reported that individuals with PWS tend to be obese due to hypothalamic-pituitary 
dysregulation which was induced by hyperphagia. This can lead to increased obesity in childhood, which progressively develops into T2DM in PWS. The excess adipose tissue produces adipokines, which are also assumed to play a role in regulating food intake in PWS patients (Burman, Ritzen, \& Lindgren, 2001; Kennedy et al., 2006; Lindmark, Trygg, Giltvedt, \& Kolset, 2010).

Alternatively, excess carbohydrates were responsible for increased adiposity and cause a decline in energy expenditure, which leads to weight gain in PWS. Obesity and weight gain are important factors that lead to insulin resistance and T2DM. In addition, daily intake of food and nutrition are additional risk factors for T2DM. The effectiveness of dietary and lifestyle modification approaches in the prevention of T2DM was provided by the Diabetes Prevention Program trials ( $\mathrm{Hu}$, van Dam, \& Liu, 2001; Knowler et al., 2002; Miller et al., 2011; Miller, Lynn, Shuster, \& Driscoll, 2011).

Several studies have shown that type and quantity of dietary carbohydrates play a crucial role in the development of impaired glucose and lipid profile and insulin resistance and increase the risk of T2DM and cardiovascular disease (CVD) (Manson \& Spelsberg, 1993). Refined grains are low in fiber and rich in carbohydrates. They have a high glycemic load (GL) and are quickly absorbed (Mizoue et al., 2006). Some studies have shown that diets with high glycemic index (GI) can increase postprandial blood glucose level and insulin demand, which in turn may develop hypertension, dyslipidemia, and insulin resistance in the long term (Khosravi-Boroujeni et al., 2013).

High BMI and homeostasis model of assessment-insulin resistance (HOMA-IR) can lead to the development of T2DM in individuals with PWS. There was a prevalence of 13.7\% (29/211) PWS patients with T2DM risk in a Korean population (Yang, Jinsup, Sung Yoon, \& Dong-Kyu, 2017), and 7-25\% of PWS have been associated with T2DM (Buiting et al., 1995; Butler et al., 2009; McCandless et al., 2011; Nicholls \& Knepper, 2001). The prevalence of T2DM (13.5\%) was revealed by another cohort study in Italian PWS patients. However, this proportion was relatively lower than the Japanese study (26.2\%). These findings suggest that the differences in the described prevalence of T2DM might have presumably resulted from various sizes of the PWS base population (Fintini et al., 2016). Nevertheless, there has been no report of T2DM associated with PWS in Tamil Nadu population, and the etiology of the development of T2DM in PWS is currently unclear.

In the present study, we analyzed the amount of food consumed and the number of servings consumed per day for each food item in both PWS and obesity control (OC) subjects. This food information was given by the parents of these subjects, using an initial short questionnaire in self-report format. Further, we compared the physical and biochemical parameters of the subjects. This study had also analyzed the genetic counseling given to all PWS patients along with parents to make a family pedigree, which provided knowledge regarding the risk and proper management leading to control of PWS. The purpose of our present study is to investigate the link between excessive carbohydrate consumption from high consumption of food consisting of white rice and development of T2DM with BMI $>30 \mathrm{~kg} / \mathrm{m}^{2}$ in PWS patients matched with OC subjects.

\section{Methods and materials Data collection}

All participants were given an initial short questionnaire in self-report format to analyze their eating behavior and physical and biochemical parameters. The data were collected from Coimbatore, Chennai, and Vellore districts in Tamil Nadu over a span of 2 years from 2015 to 2017. The PWS patients were initially selected based on phenotype characteristics such as low birth weight, hypotonia, and feeding difficulties in infancy, followed by excessive appetite, obesity, small hands and feet, almond-shaped eyes, narrow bifrontal, scoliosis, short stature, and intellectual disabilities (average IQ of 65) in early childhood. The selected participants were then genetically confirmed for PWS by methylation study. The study was approved by the Institute Ethical Committee, and written, informed consent form was obtained from all the participants before beginning the study.

\section{Subject recruitment}

A total of 46 participants comprising of 23 PWS patients grouped into adolescents $(n=13)$ [9 males and 4 females] and adults $(n=10)$ [7 males and 3 females] along with 23 OC subjects comprising adolescents $(n=12)[7$ males and 5 females] and adults $(n=11)$ [ 6 males and 5 females] were recruited for the present study. The patients and control subjects were categorized based on age (adolescent 12-19 years and adult 20-28 years), weight, height, and BMI (weight in $\mathrm{kg} /$ height in $\mathrm{m}^{2}$ ). BMI was divided into two categories, viz., obese (BMI $\geq$ 30) and overweight (BMI 25-29.9). All the PWS subjects were found to be associated with obesity (BMI $\geq 30$ ), while OC subjects were found to be either overweight $(n=13)$ [BMI 25-29.9] or obese $(n=10)$ [BMI $\geq 30]$. Type 2 diabetes mellitus was also a criterion for selecting the participants of this study. All 23 PWS participants had T2DM (13 adolescents and 10 adults), whereas only 7 among the 23 OC subjects had T2DM (3 adolescents and 4 adults). The biochemical parameters of all the participants are reported in Additional file 1: Table S1a and b. 


\section{Genetic counseling}

We conducted genetic counseling for all the participants along with their parents. A questionnaire was prepared and was recorded face-to-face with the participants and their family members present. The questionnaire had standard demographic data as well as data relating to the behavior of patients, communication, food habit, lifestyle, medication, physical activity, recent infections, vaccinations, and diagnostic tests. Pedigree analysis was carried out based on the data collected, and genetic counseling was given to educate the patients and their parents about the syndrome and its diagnosis and management.

\section{Food consumption data}

With the help of the questionnaire, information was collected based on the amount of food intake and the number of servings consumed per day for each food item. Daily intake of grams of food and calories ( $g$, $\mathrm{kcal} /$ day) of each food item was calculated by multiplying the amount of food intake and the number of servings per day. We used a mean $\pm \mathrm{SD}$ calculation for comparing food and calorie intake (g, kcal/day) of each item for three different categories: PWS, OC with T2DM, and OC without T2DM.

\section{Statistical analysis}

Physical parameters such as weight, height, age, sex, BMI, and biochemical parameters were compared between PWS and OC subjects using mean \pm SD values. Comparison of daily total intake of food and macronutrients was done using mean $\pm \mathrm{SD}$. The Student $t$ test was used to verify the significance levels in $p>0.05$ of each in the PWS and OC subjects. All statistical analyses were performed by using SPSS software version 22 .

\section{Result}

\section{Characteristics of participants}

Characteristics of the PWS and OC subjects are provided in Table 1. A total of 23 PWS patients comprising of adolescents and adults along with OC $(n=23)$ were recruited for the present study. Both male $[n=16$ (69.56\%)] and female $[n=7$ (30.43\%)] PWS subjects were taken into consideration. Based on their age, they were divided into two categories: adolescents $[n=13$ $(56.52 \%)]$ and adults $[n=10(43.47 \%)]$. All 23 PWS subjects $(100 \%)$ were associated with obesity (BMI $\geq 30$ ), and T2DM was observed in all PWS subjects $(n=23$ [100\%]). These characteristics were compared with 23 obesity control (OC) subjects comprising of male $[n=$ $13(56.52 \%)]$ and female $[n=10(43.47 \%)]$ members. As with PWS, based on their age, they were divided into two categories: adolescents $[n=12(52.17 \%)]$ and adults $[n=11(47.82 \%)]$. The BMI range of OC subjects was
Table 1 General characteristic of the study population in PWS and obese control

\begin{tabular}{|c|c|c|}
\hline Characteristics & PWS, $n=23$ & Obese, $n=23$ \\
\hline \multicolumn{3}{|l|}{ Sex, $N(\%)$} \\
\hline Male & $16(69.56)$ & $13(56.52)$ \\
\hline Female & $7(30.43)$ & $10(43.44)$ \\
\hline \multicolumn{3}{|l|}{ Age categories, N (\%) } \\
\hline Adolescent, 12-19years & $13(56.52)$ & $12(52.17)$ \\
\hline Adult, 20-28 years & $10(43.47)$ & $11(47.82)$ \\
\hline \multicolumn{3}{|l|}{ BMI, N (\%) } \\
\hline Overweight (BMI 25-29.9) & $\mathrm{Nil}$ & $13(56.52)$ \\
\hline Obese (BMI $\geq 30$ ) & $23(100)$ & $10(43.44)$ \\
\hline \multicolumn{3}{|l|}{ Type 2 diabetes mellitus, N (\%) } \\
\hline Adolescent, 13 & $(56.52)$ & $3(13.04)$ \\
\hline Adult, 10 & $(43.44)$ & $4(17.39)$ \\
\hline
\end{tabular}

Description of general characteristics for participant's subject. PWS Prader-Willi syndrome, $B M I$ body mass index, NA the individual with PWS not present in overweight

from overweight (BMI 25-29.9) $[n=13(56.52 \%)]$ to obese $(\mathrm{BMI} \geq 30)[n=10(43.47 \%)]$. Of the $23 \mathrm{OC}$ subjects, only 7 had T2DM, adolescents $(n=3[13.04 \%])$ and adults $(n=4[17.39 \%])$.

\section{Comparison of physical and biochemical parameters}

The physical and biochemical parameters were compared between adolescents and adults in PWS vs. OC subjects using total mean \pm SD values given in Table 2 . Age was matched with adolescents $(15.4 \pm 2.3$ vs. $15 \pm$ 2.5 [ $p$ value 0.6807$])$ and adults $(25.1 \pm 2.6$ vs. $24 \pm 2.4$ [ $p$ value 0.3279$]$ ), and there was no significance in age group. Height (in $\mathrm{cm}$ ) in adolescents $(108.7 \pm 2.8$ vs. $129.5 \pm 5.1)$ and adults $(119.9 \pm 4.6$ vs. $141.4 \pm 9.4)$, weight (in $\mathrm{kg}$ ) in adolescents $(61.5 \pm 7.1 \mathrm{vs} .46 .4 \pm 6.7)$ and adults $(86.9 \pm 6.6$ vs. $63.4 \pm 8.3)$, and BMI (in $\left.\mathrm{kg} / \mathrm{m}^{2}\right)$ in adolescents $(51.9 \pm 4.5$ vs. $27.4 \pm 2)$ and adults $(60.5 \pm 4.4$ vs. $31.6 \pm 3.3)$ were matched. Their $p$ value was $<0.0001$, suggesting that there was extreme significance in height, weight, and BMI. The PWS patients were found to be associated with obesity than the OC subjects. The cholesterol $(\mathrm{mg} / \mathrm{dl})$ levels in adolescents $(229.5 \pm 13.3$ vs. $210.1 \pm$ 22.6 [ $p$ value 0.0146$])$ and adults $(239.8 \pm 11.7$ vs. $216.2 \pm$ 17.3 [ $p$ value 0.0018$]$ ) showed a significance for both PWS and $\mathrm{OC}$ subjects. A comparison of the urine glucose and blood sugar levels was done in PWS with T2DM patients as well as in OC with T2DM patients. Though glucose levels in the urine of adolescents ( $3 \pm 1.0$ vs. $2.6 \pm 1.1$ [ $p$ value 0.5482$])$ and adults $(2.6 \pm 1.3$ vs. $3.2 \pm 0.5$ [ $p$ value $0.1711])$ showed no significance for both PWS and OC subjects, the fasting blood sugar levels in adolescents $(202.8 \pm 14.2$ vs.124.9 $\pm 45.6[p$ value $<0.0001])$ and adults $(199.5 \pm 14.1$ vs. $134.6 \pm 58.0$ [ $p$ value 0.0027$])$ showed extremely significant values. Similarly, postprandial blood 
Table 2 Comparison of physical and biochemical parameters between PWS and OC subjects

\begin{tabular}{|c|c|c|c|c|c|c|c|}
\hline \multirow[t]{2}{*}{ Characteristic } & \multicolumn{2}{|l|}{ PWS } & \multicolumn{2}{|l|}{ OC } & \multicolumn{2}{|l|}{ Total } & \multirow[t]{2}{*}{$p$ value } \\
\hline & Male & Female & Male & Female & PWS & OC & \\
\hline \multicolumn{8}{|l|}{ Adolescent, 12-19years } \\
\hline$N$ & 9 & 4 & 7 & 5 & 13 & 12 & \\
\hline Age (years) & $15.5 \pm 2.0$ & $15.2 \pm 3.3$ & $16.2 \pm 2.4$ & $14.8 \pm 3.0$ & $15.4 \pm 2.3$ & $15 \pm 2.5$ & 0.6807 \\
\hline Height (cm) & $109.3 \pm 2.4$ & $107.5 \pm 3.6$ & $130 \pm 5.0$ & $129 \pm 5.8$ & $108.7 \pm 2.8^{* *}$ & $129.5 \pm 5.1$ & $<0.0001$ \\
\hline Weight (kg) & $62.4 \pm 7.3$ & $59.5 \pm 7.1$ & $43.7 \pm 5.9$ & $44 \pm 5.1$ & $61.5 \pm 7.1^{* *}$ & $46.4 \pm 6.7$ & $<0.0001$ \\
\hline $\mathrm{BMI}\left(\mathrm{kg} / \mathrm{m}^{2}\right)$ & $52.1 \pm 5.0$ & $51.3 \pm 3.7$ & $27.6 \pm 2.9$ & $27.0 \pm 2.2$ & $51.9 \pm 4.5^{* *}$ & $27.4 \pm 2.5$ & $<0.0001$ \\
\hline Cholesterol (mg/dl) & $233.5 \pm 13.4$ & $220.5 \pm 8.3$ & $213.2 \pm 18.6$ & $205.8 \pm 29.0$ & $229.5 \pm 13.3^{*}$ & $210.1 \pm 22.6$ & 0.0146 \\
\hline Glucose & $3.3 \pm 1.4$ & $4 \pm 0.8$ & $3 \pm 1.4$ & $1 \pm 1.4$ & $3 \pm 1.0$ & $2.6 \pm 1.1$ & 0.5482 \\
\hline Fasting blood sugar & $200.5 \pm 16.1$ & $208 \pm 7.9$ & $131.4 \pm 46.5$ & $115.8 \pm 48.0$ & $202.8 \pm 14.2^{* *}$ & $124.9 \pm 45.6$ & $<0.0001$ \\
\hline Postprandial blood sugar & $287.5 \pm 52.7$ & $317 \pm 31.8$ & $200.1 \pm 77.2$ & $211 \pm 66.61$ & $296.6 \pm 48.0^{* *}$ & $204.6 \pm 70.0$ & 0.0008 \\
\hline \multicolumn{8}{|l|}{ Adult, 20-28 years } \\
\hline$N$ & 7 & 3 & 6 & 5 & 10 & 11 & \\
\hline Age (years) & $25.8 \pm 2.1$ & $23.3 \pm 3.2$ & $23.5 \pm 3.0$ & $24.6 \pm 1.6$ & $25.1 \pm 2.6$ & $24 \pm 2.4$ & 0.3279 \\
\hline Height (cm) & $120 \pm 5.41$ & $119.6 \pm 8.3$ & $139.5 \pm 11.3$ & $143.8 \pm 7.0$ & $119.9 \pm 4.6^{* *}$ & $141.4 \pm 9.4$ & $<0.0001$ \\
\hline Weight (kg) & $88.8 \pm 7.1$ & $82.3 \pm 0.5$ & $55.3 \pm 7.2$ & $62.6 \pm 6.6$ & $86.9 \pm 6.6^{* *}$ & $63.4 \pm 8.3$ & $<0.0001$ \\
\hline $\mathrm{BMI}\left(\mathrm{kg} / \mathrm{m}^{2}\right)$ & $61.7 \pm 4.5$ & $57.5 \pm 2.9$ & $28.5 \pm 3.3$ & $31.8 \pm 2.8$ & $60.5 \pm 4.4^{* *}$ & $31.6 \pm 3.3$ & $<0.0001$ \\
\hline Cholesterol (mg/dl) & $238.2 \pm 10.0$ & $243.3 \pm 17.0$ & $210.6 \pm 12.5$ & $223 \pm 21.3$ & $239.8 \pm 11.7^{*}$ & $216.2 \pm 17.3$ & 0.0018 \\
\hline Glucose & $3.57 \pm 1.6$ & $3 \pm 1.7$ & $3 \pm 0.1$ & $3.5 \pm 0.7$ & $2.6 \pm 1.3$ & $3.2 \pm 0.5$ & 0.1711 \\
\hline Fasting blood sugar & $199.2 \pm 16.8$ & $200 \pm 7$ & $128.5 \pm 61.0$ & $142 \pm 60.3$ & $199.5 \pm 14.1^{*}$ & $134.6 \pm 58.0$ & 0.0027 \\
\hline Postprandial blood sugar & $307.5 \pm 52.1$ & $280 \pm 31.5$ & $225.8 \pm 57.3$ & $243.8 \pm 73.4$ & $299.3 \pm 47.0^{\dagger}$ & $234 \pm 62.4$ & 0.0146 \\
\hline
\end{tabular}

The physical and biochemical parameters were calculated by using mean (SD) in both subjects, and all data are reported in Additional file 1: Table S1a and b. PWS, Prader-Willi syndrome, OC obesity control, BMI body mass index, SD, standard deviation. *** $p$ values are extremely significant, ${ }^{*} p$ values are highly significant; ${ }^{\dagger} p$ values are significant

sugar in adolescents $(296.6 \pm 48.0$ vs. $204.6 \pm 70.0[p$ value 0.0008$])$ and adults $(299.3 \pm 47.0$ vs. $234 \pm 62.4$ [ $p$ value 0.0146$]$ ) showed highly significant values proving that PWS patients were at a higher risk of T2DM when compared to OC subjects.

\section{High intake of food and calories: the risk factors for T2DM and obesity in PWS and OC}

Details of the daily intake of total grams of food and calories ( $\mathrm{g}, \mathrm{kcal} /$ day) for each food item are provided in Additional file 1: Table S2a and b for both PWS and OC subjects. The total intake of white rice, milk and dairy products, instant food, and meat in PWS subjects was significantly higher when compared to OC subjects $(p$ value 0.05 ) with and without T2DM. In contrast, the intake of sugar and sweets, beverage, oil and fat, egg, and fish in OC subjects with and without T2DM was significantly higher than that of the PWS patients ( $p$ value 0.05). Furthermore, the current study showed the following order of increasing white rice intake than any other food: OC without T2DM > OC with T2DM > PWS patients. Specifically, the intake of white rice in PWS $(1071 \mathrm{~g}, 1370 \mathrm{kcal} /$ day $)$ was more when compared to OC with T2DM $(814 \mathrm{~g}, 1058 \mathrm{kcal} /$ day $)$ and OC without
T2DM (158 g, $215 \mathrm{kcal} /$ day), which depicts the significantly higher intake of white rice in both adolescent and adult groups of PWS subjects than those in OC subjects ( $p$ value 0.05) which were shown in Table 3. Figure 1 depicts the comparison of food and calorie intake per day for each food item in PWS, OC with T2DM, and $\mathrm{OC}$ without T2DM.

Table 4 shows a comparison of the consumption of macronutrients from daily intake of white rice and BMI in PWS, OC with T2DM, and OC without T2DM subjects using mean \pm SD values. Too much of carbohydrate consumption from total intake of white rice compared to any other macronutrients was observed in PWS patients. Statistical analysis shows high BMI value (55.6 \pm 6.17) and more carbohydrate consumption (300.2 \pm 81.6 g/day) in PWS, followed by OC with T2DM subjects [BMI $(30.2 \pm 4.14)$, carbohydrate consumption $(225.3 \pm$ $32.5 \mathrm{~g} /$ day)] and then by OC without T2DM [BMI (29.1 $\pm 3.5)$, carbohydrate consumption $(88.0 \pm 20.2 \mathrm{~g} /$ day $)]$. From this finding, we conclude that PWS subjects consume significantly more carbohydrates, and they have exceeding BMI values, when compared to $\mathrm{OC}$ subjects with and without T2DM ( $p$ value 0.05 ). Additionally, we compared macronutrient intake and BMI values between 


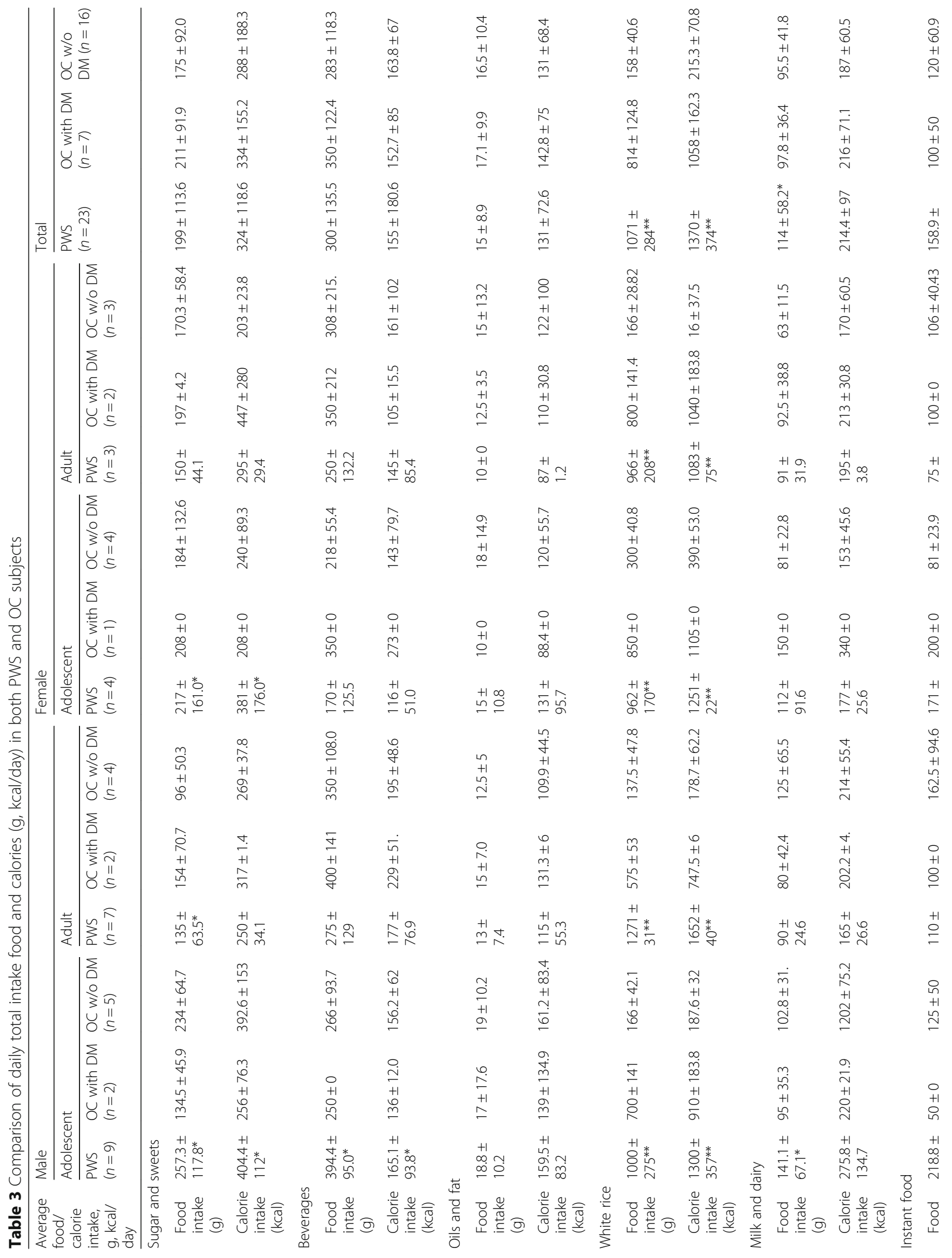




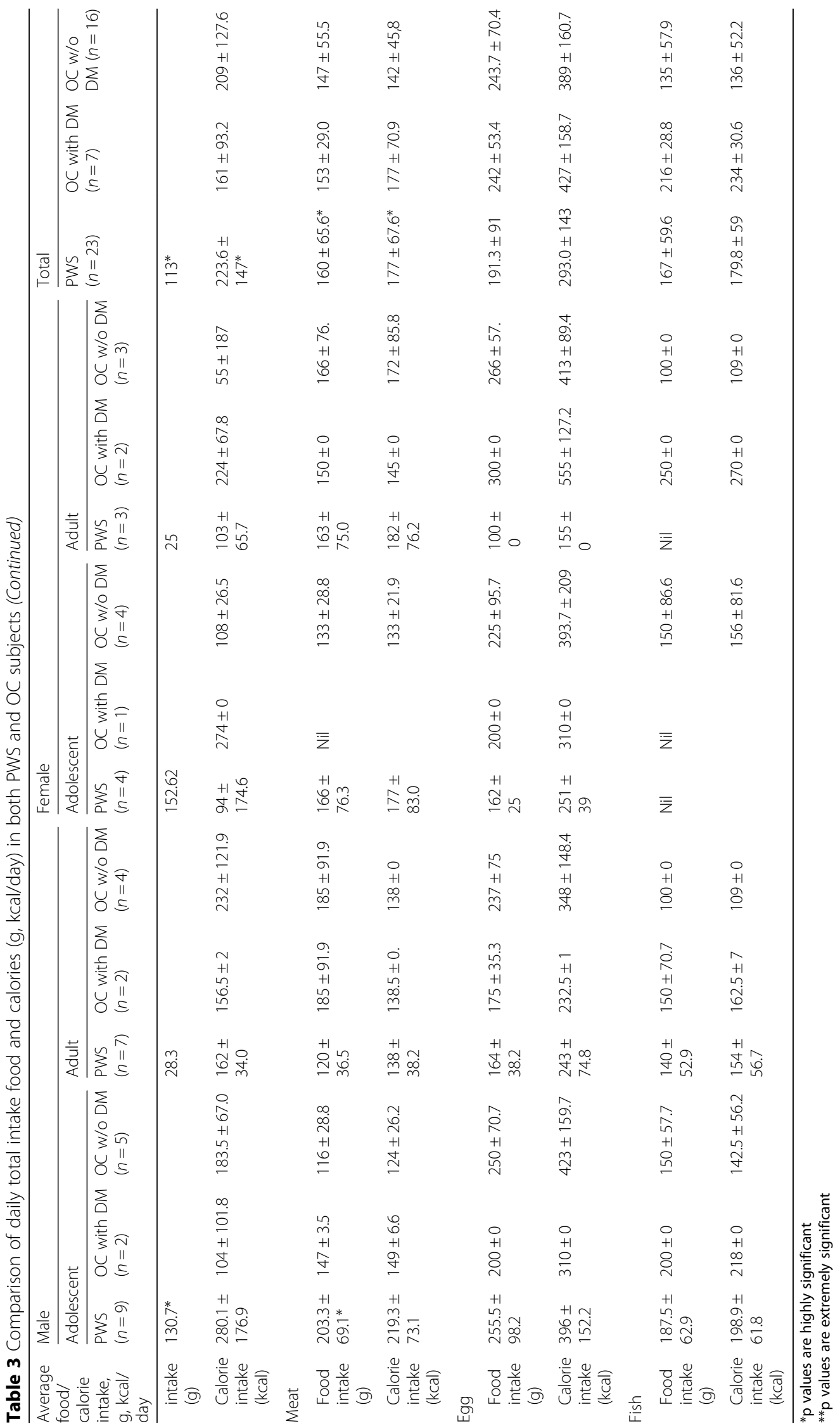




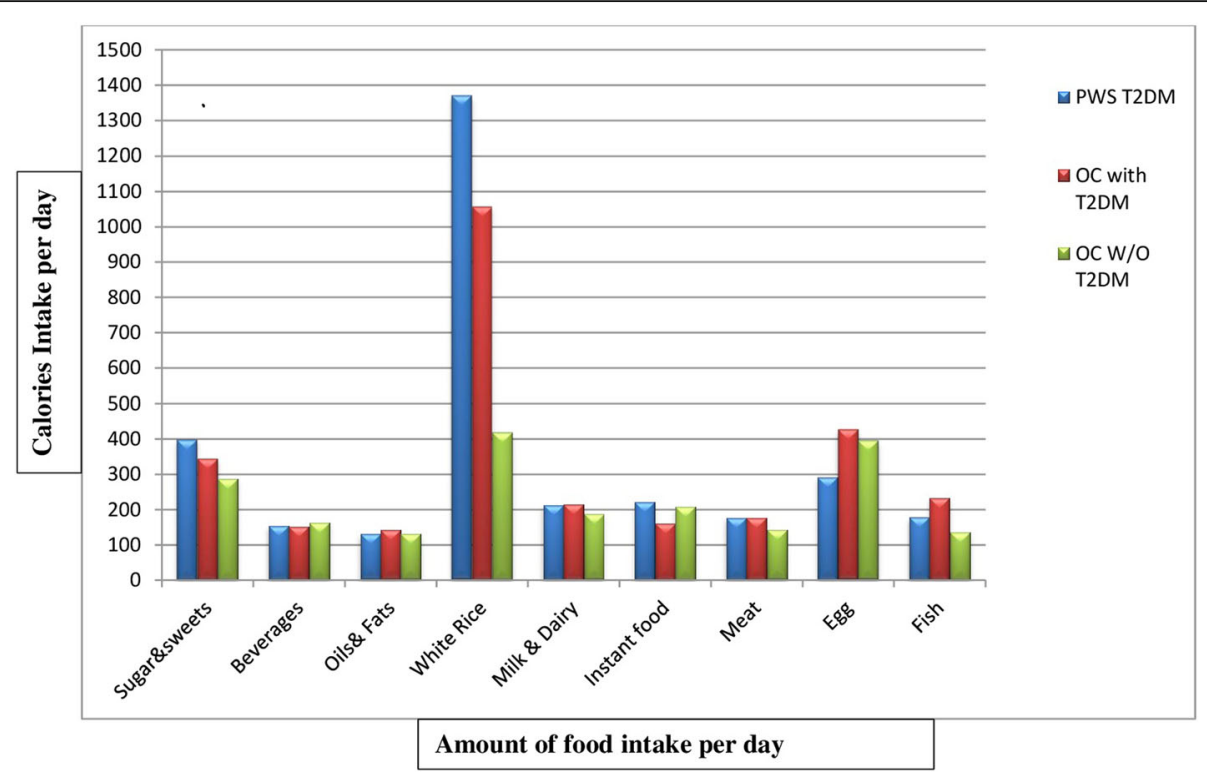

Fig. 1 Comparison of food and calorie intake per day for each food item in PWS and OC subject. The figure depicts the comparison of food and calorie intake per day for each food item in PWS, OC with T2DM, and OC without T2DM. The total intake of white rice, milk and dairy, instant food, and meat in PWS subjects was significantly higher when compared to that in OC subjects with T2DM and without T2DM ( $p$ value 0.05). In contrast, the intake of sugar and sweets, beverage, oil and fat, egg, and fish in OC subjects both with T2DM and without T2DM was significantly higher than that in PWS subjects ( $p$ value 0.05 )

adolescents and adults in PWS, OC with T2DM, and $\mathrm{OC}$ without T2DM. The results reveal that the macronutrient consumption in the adult group was more significant ( $p$ value 0.05 ) than that in the adolescent group of both PWS and OC subjects.

\section{Discussion}

To our knowledge, this is the first study to investigate the eating behavior focusing on the high amount of carbohydrates consumed from daily intake of white rice and BMI as risk factors for T2DM in PWS patients in Tamil Nadu population. The present study showed that all 23 PWS patients were associated with BMI values exceeding $30 \mathrm{~kg} / \mathrm{m}^{2}$, whereas among the non-syndromic OC subjects, only 13 individuals were overweight (BMI value $25-29.9 \mathrm{~kg} / \mathrm{m}^{2}$ ) and 10 individuals were obese (BMI value $>30 \mathrm{~kg} / \mathrm{m}^{2}$ ). From this, we determine that BMI values are extremely significant $(p<0.0001)$ in PWS subjects than those in OC subjects. This study also showed that all 23 (100\%) PWS patients in both adolescent and adult categories had been contributing to T2DM, whereas only 7 among the 23 OC subjects had T2DM. According to the previous study, severe obesity was developed by exceeding BMI values of $26-28 \mathrm{~kg} / \mathrm{m}^{2}$, making it possible for insulin secretion and the development of diabetes (Campbell \& Gerich, 1990). The individuals with PWS

Table 4 Comparison of macronutrient consumption from white rice intake and BMI value in both PWS and OC subjects

\begin{tabular}{|c|c|c|c|c|c|c|c|c|c|}
\hline \multirow{2}{*}{$\begin{array}{l}\text { Macronutrient } \\
\text { consumption } \\
\text { per day } \\
\text { and BMl }\end{array}$} & \multicolumn{3}{|l|}{ Adolescent } & \multicolumn{3}{|l|}{ Adult } & \multicolumn{3}{|l|}{ Total } \\
\hline & PWS $(n=13)$ & $\begin{array}{l}\text { OC with DM } \\
(n=3)\end{array}$ & $\begin{array}{l}\text { OC w/o DM } \\
(n=9)\end{array}$ & PWS $(n=10)$ & $\begin{array}{l}\text { OC with DM } \\
(n=4)\end{array}$ & $\begin{array}{l}\text { OC w/o DM } \\
(n=7)\end{array}$ & PWS $(n=23)$ & $\begin{array}{l}\text { OC with DM } \\
(n=7)\end{array}$ & $\begin{array}{l}\text { OC w/o DM } \\
(n=16)\end{array}$ \\
\hline $\begin{array}{l}\text { Total energy } \\
\text { (kcal) }\end{array}$ & $1285 \pm 313.0$ & $975 \pm 171.9$ & $231.1 \pm 80.3$ & $1482 \pm 434.1$ & $1121.2 \pm 144.1$ & $195 \pm 53.0$ & $1370.6 \pm 374.8$ & $814.2 \pm 124.8$ & $411.6 \pm 94.0$ \\
\hline Protein (g) & $26.27 \pm 6.69$ & $19.7 \pm 3.1$ & $8.3 \pm 2.1$ & $31.74 \pm 8.39$ & $23.0 \pm 2.7$ & $8.45 \pm 1.8$ & $28.6 \pm 7.8$ & $21.6 \pm 3.1$ & $8.4 \pm 1.9$ \\
\hline Fat (g) & $2.7 \pm 0.69$ & $2.0 \pm 0.3$ & $0.87 \pm 0.21$ & $3.30 \pm 0.8$ & $2.38 \pm 0.28$ & $0.88 \pm 0.19$ & $2.98 \pm 0.8$ & $2.2 \pm 0.3$ & $0.87 \pm 0.2$ \\
\hline $\begin{array}{l}\text { Carbohydrates } \\
\text { (g) }\end{array}$ & $275.1 \pm 70.0$ & $206.5 \pm 32.5$ & $87.6 \pm 22.0$ & $330.4 \pm 90.0$ & $239.4 \pm 28.1$ & $88.5 \pm 19.4$ & $300.2 \pm 81.6^{*}$ & $225.3 \pm 32.5$ & $88.0 \pm 20.2$ \\
\hline Fiber (g) & $4.06 \pm 1.03$ & $2.9 \pm 0.4$ & $1.2 \pm 0.31$ & $4.72 \pm 1.24$ & $3.4 \pm 0.4$ & $1.25 \pm 0.2$ & $4.2 \pm 1.1$ & $3.2 \pm 0.4$ & $1.25 \pm 0.2$ \\
\hline BMI & $51.9 \pm 4.5$ & $27.1 \pm 3.2$ & $27.5 \pm 2.5$ & $60.51 \pm 4.4$ & $32.6 \pm 3.1$ & $31.1 \pm 3.6$ & $55.6 \pm 6.17^{*}$ & $30.2 \pm 4.14$ & $29.1 \pm 3.5$ \\
\hline
\end{tabular}

PWS subjects showed high significant of BMI value and excessive carbohydrate consumption of $>300 \mathrm{~g} /$ day from white rice intake compared with OC subjects. PWS, Prader-Willi syndrome, OC obesity control, $B M I$ body mass index, OC with DM obesity control with diabetes mellitus, OC w/o DM obesity control without diabetes mellitus. *High significant value 
may have relative insulin sensitivity, insulin resistance, and obesity, which are the most important factors for the occurrence of T2DM via destruction of $\beta$ cell function (Fintini et al., 2016; L'Allemand, Eiholzer, Schlumpf, Torresani, \& Girard, 2003). Yang et al. (2017) had reported that in PWS, increased BMI and homeostasis model of assessment-insulin resistance (HOMA-IR) can lead to the development of T2DM. Furthermore, the prevalence of T2DM about 22.3/1000 in 10-14-year-old children was found in specific ethnic subgroups such as AfricanAmerican, Hispanic, Asian/Pacific Islanders, and American Indians, being highest in Pima Indians (Lindmark et al., 2010), and other studies reported the prevalence of T2DM about 0.4 to $1 \%$ in obese children of age $\geq 12$ years (Sinha et al., 2002; Wabitsch et al., 2004).

Likewise, a prevalence of $13.7 \%$ (29/211) was shown in PWS patients with T2DM risk in a study conducted in a Korean population (Yang et al., 2017). Moreover, the prevalence of T2DM (13.5\%) was revealed by another cohort study in Italian PWS patients. However, this proportion is relatively lower than that of PWS develops T2DM if BMI $>30 \mathrm{~kg} / \mathrm{m}^{2}$. The difference in the prevalence of T2DM in PWS depends on the size of the PWS base population and their lifestyle factors.

Furthermore, obesity and weight gain are important factors that lead to insulin resistance and T2DM. Daily intake of food and nutrition are other risk factors for T2DM. The effectiveness of dietary and lifestyle modification approaches in the prevention of T2DM was provided by the Diabetes Prevention Program trial (Hu et al., 2001; Knowler et al., 2002). Several prospective studies have reported a positive association between white rice intake and diabetes (Nanri et al., 2010; Sun et al., 2010; Villegas et al., 2007). For instance, seven prospective cohort studies conducted a meta-analysis in Asian and Western populations and showed that an overall $27 \%$ increased risk of diabetes matched with high versus low white rice consumption levels. Furthermore, another study has reported a 55\% increased risk of diabetes when consuming larger quantities of white rice in the Asian population (Wabitsch et al., 2004). The Japanese Public Health Center-based prospective study conducted in women showed $65 \%$ increased risk of diabetes with a daily intake of cooked white rice ( $>437 \mathrm{~g}$ ) when compared to consuming $<287$ g/day (Nanri et al., 2010; Wabitsch et al., 2004). Similarly, the Shanghai Women's Health Study reported a 78\% higher risk of diabetes with daily raw white rice intake of $>300 \mathrm{~g} /$ day when compared to $<200 \mathrm{~g}$ of raw white rice intake. Although the exact mechanism of increased risk of diabetes through intake of white rice is not clear, several prospective cohort studies provided that both the GI and glycemic load have been associated with increased risk of metabolic syndrome and diabetes (Villegas et al., 2007; Salmeron, Ascherio, et al., 1997; Salmeron,
Manson, et al., 1997; Hu, Pan, Malik, \& Sun, 2012; Oba et al., 2013). Likewise, another study revealed that the GI of white rice depends on the proportion of the amylose content of the grain in addition to the cooking time, and the GI value of white rice has been reported to be higher than that of brown rice and other whole grains (Foster-Powell, Holt, \& Brand-Miller, 2002). Other two prospective cohort studies in Iran observed a doubling of diabetes risk associated with $>250 \mathrm{~g}$ of white rice intake in Tehran Lipid and Glucose Study (TLGS) when compared to Golestan Cohort Study (GCS) (Golozar et al., 2017). Similarly, our current study has reported that individuals with PWS highly consumed white rice (1071 g, $1370 \mathrm{kcal} /$ day) matched with another daily intake of foods. In contrast, daily intake of white rice was only $814 \mathrm{~g}, 1058 \mathrm{kcal}$, in $7 \mathrm{OC}$ subjects with T2DM and 158 g, $215 \mathrm{kcal}$, intakes by 16 of OC without T2DM. These findings suggest that our study populations of PWS mostly consumed white rice in comparison with the OC subjects. This is because of the fact that white rice is the staple food for Indian populations, especially for southern populations. So, they consume it three times a day. White rice contains more carbohydrates, low fiber, and nutrients (proteins and vitamins). The excess carbohydrates are responsible for the increased adiposity and GI, which might lead to weight gain and T2DM.

The previous study found that increased carbohydrate intake mainly from white rice may increase T2DM in East Asian populations (Brown et al., 2009). Higher carbohydrate intake was associated with a serious risk of diabetes with BMI $\geq 25 \mathrm{~kg} / \mathrm{m}^{2}$ in obese subjects, and this finding suggested that their carbohydrate intakes should be within the desirable energy proportions $(50-65 \%$ energy) to prevent the development of type 2 diabetes in Japanese population (Villegas et al., 2007; Sakurai et al. 2016). Other investigations reported that high intake of carbohydrates from starchy foods contributes more strongly to metabolic disorders and hyperlipidemia, and this study suggested that the optimal daily intake of carbohydrates from starchy foods is $220 \mathrm{~g}$ for the prevention of metabolic disorders in Northern China (Feng et al., 2015). A human clinical trial provides that consuming high carbohydrate diets decreases the level of HDL-C and increases TG and TC levels, and low carbohydrate consumption has the opposite effects because high-fat diets tend to lower serum TG and LDL-C and increase HDL-C, which promote weight loss (Nordmann et al., 2006; Song et al., 2012). Excess carbohydrates are responsible for increased adiposity and reduced energy expenditure, which must be responsible for the weight gain in PWS (Miller, Lynn, Shuster, \& Driscoll, 2011; Miller, Lynn, Driscoll, et al., 2011), and Miller, Lynn, Shuster, and Driscoll (2013) had advised the parents of these children to decrease their energy intake at the 
same time placing the children on a healthy, well-balanced diet of approximately 30\% fat, $45 \%$ carbohydrates, and $25 \%$ protein, with the carbohydrates given as complex carbohydrates to provide a goal of $20 \mathrm{~g}$ of fiber per day to prevent of weight gain in PWS. In our current study, we found out that individuals of PWS were associated with high consumption of carbohydrates (300.2 \pm $81.6 \mathrm{~g} /$ day) and high BMI values (55.6 \pm 6.17$)$. Similarly, OC with T2DM subjects have BMI $30.2 \pm 4.14$, and their carbohydrate consumption is $225.3 \pm 32.5 \mathrm{~g} /$ day, which is higher when compared to OC without T2DM [BMI (29.1 $\pm 3.5)$, carbohydrate consumption $(88.0 \pm 20.2 \mathrm{~g} /$ day $)]$.

This study also reports fasting blood sugar levels $(p$ value 0.0027$)$ and postprandial blood sugar levels ( $p$ value 0.0146 ) that are highly significant in PWS when compared to OC subjects. Hence, this current study strongly suggests that high consumption of carbohydrates could also increase the blood sugar level and it is responsible for serious risk for the development of T2DM with those of exceeding BMI in the individuals with PWS. Furthermore, based on our finding and other previous related papers, we opine that individuals with PWS consume foods high in carbohydrates, which depends on the staple foods and it varies place to place. Since white rice is the staple food for South Indian population, the PWS patients consume $300 \mathrm{~g}$ of carbohydrates per day.

Limitation of this present study is that only few PWS patients' data were collected. Hence, this study was not able to show the prevalence of PWS with T2DM in our populations. Since there were no previous studies regarding daily high intake of food in PWS leading to T2DM, we could not compare our study with similar works.

\section{Conclusion}

Our current study presents the first report on excessive carbohydrate consumption by PWS patients in Tamil Nadu and their BMI $\geq 30 \mathrm{~kg} / \mathrm{m}^{2}$ as risk factors for T2DM in them. The population with PWS consumes more carbohydrates from high intake of white rice than the OC subjects. We strongly suggest that $>300 \mathrm{~g}$ of carbohydrate consumption from white rice intake is able to pose a high risk of T2DM in PWS. We have also found that morbid obesity is the additional predictive factor for the development of T2DM. Since high carbohydrate consumption and $\mathrm{BMI} \geq 30 \mathrm{~kg} / \mathrm{m}^{2}$ are the strong predictive factors, optimal daily consumption of carbohydrates from white rice is recommended for the prevention of development of T2DM in PWS and other metabolic disorders with T2DM. Further longitudinal studies in Tamil Nadu are required to better understand the endocrine and metabolic factors that can determine T2DM development in PWS individuals.

\section{Additional file}

Additional file 1: Table S1. a Characteristics of BMI, biochemical parameters, and diabetes mellitus in PWS. b Characteristics of BMI, biochemical parameters, and diabetes mellitus in OC. Table S2. a Supplementary table of daily food intakes $\mathrm{g}$, kcal/per day in PWS. b Supplementary table of daily food intakes $\mathrm{g}$, kcal/day in OC subjects. (DOCX $42 \mathrm{~kb})$

\section{Abbreviations}

BMI: Body mass index; OC with DM: Obesity control with diabetes mellitus; OC without DM: Obesity control without diabetes mellitus; OC: Obesity control; PWS: Prader-Willi syndrome; T2DM: Type 2 diabetes mellitus

\section{Acknowledgements}

The authors would like to thank the authorities of Bharathiar University, India, for providing necessary facilities for conducting this article and we thank all individuals who provided their data, blood sample and consent for genetic analysis.

\section{Funding}

This present research study had not received any specific grant from funding agencies.

\section{Availability of data and materials}

The relevant data and materials are available in the present study.

\section{Authors' contributions}

PV, AN, and BV contributed to the design of the study. Data was analyzed by PV. BV and PV performed the statistical study. PV wrote the paper. AN checked the grammar and spelling. PV is responsible for validating the data and this work. All authors read and approved the final manuscript.

\section{Ethics approval and consent to participate}

The study was approved by the Institute Ethical Committee of Bharathiar University, India, and also informed consent was obtained from all individual participants included in the study.

\section{Consent for publication}

Not applicable.

\section{Competing interests}

The authors declare that they have no competing interests.

\section{Publisher's Note}

Springer Nature remains neutral with regard to jurisdictional claims in published maps and institutional affiliations.

\section{Author details}

${ }^{1}$ Human Molecular Cytogenetics and Stem Cell Laboratory, Department of Human Genetics and Molecular Biology, Bharathiar University, Coimbatore, Tamil Nadu 641046, India. ${ }^{2}$ Disease Proteomics Laboratory, Department of Zoology, Bharathiar University, Coimbatore, Tamil Nadu 641046, India.

Received: 3 October 2018 Accepted: 11 December 2018

Published online: 29 December 2018

\section{References}

Bittel, D. C., \& Butler, M. G. (2005). Prader-Willi syndrome: clinical genetics, cytogenetics and molecular biology. Expert Reviews in Molecular Medicine, $7(14), 1-20$.

Brown, I. J., Elliott, P., Robertson, C. E., Chan, Q., Daviglus, M. L., Dyer, A. R., et al. (2009). Dietary starch intake of individuals and their blood pressure: the International Study of Macronutrients and Micronutrients and Blood Pressure. Journal of Hypertension, 27, 231-236.

Buiting, K., Saitoh, S., Gross, S., Dittrich, B., Schwartz, S., Nicholls, R. D., et al. (1995). Inherited micro deletions in the Angelman and Prader-Willi syndromes define an imprinting centre on human chromosome 15. Nature Genetics, 9, 395-400. 
Burman, P., Ritzen, E. M., \& Lindgren, A. C. (2001). Endocrine dysfunction in Prader-Willi syndrome: a review with special reference to $\mathrm{GH}$. Endocrine Reviews, 22, 787-799.

Butler, M. G., Jennifer, S., Myers, S. E., Gold, J. A., Virginia, K., \& Driscoll, D. J. (2009). Is gestation in Prader-Willi syndrome affected by the genetic subtype? Journal of Assisted Reproduction and Genetics, 26(8), 461-466.

Campbell, P. J., \& Gerich, J. E. (1990). Impact of obesity on insulin action in volunteers with normal glucose tolerance: demonstration of a threshold for the adverse effect of obesity. The Journal of Clinical Endocrinology and Metabolism, 70, 1114-1118.

Feng, R., Du, S., Chen, Y., Zheng, S., Zhang, W., Na, G., et al. (2015). High carbohydrate intake from starchy foods is positively associated with metabolic disorders: a cohort study from a Chinese population. Scientific Reports, 5, 16919.

Fintini, D., Grugni, G., Bocchini, S., Brufani, C., Di Candia, S., Corrias, A., et al. (2016). Disorders of glucose metabolism in Prader-Willi syndrome: results of a multicenter Italian cohort study. Nutrition, Metabolism, and Cardiovascular Diseases, 26, 842-847.

Foster-Powell, K., Holt, S. H., \& Brand-Miller, J. C. (2002). International table of glycemic index and glycemic load values. The American Journal of Clinical Nutrition, 76(1), 5-56.

Golozar, A., Khalili, D., Etemadi, A., Poustchi, H., Fazeltabar, A., Hosseini, F., et al. (2017). White rice intake and incidence of type-2 diabetes: analysis of two prospective cohort studies from Iran. BMC Public Health, 17, 133.

Hu, E. A., Pan, A., Malik, V., \& Sun, Q. (2012). White rice consumption and risk of type 2 diabetes: meta-analysis and systematic review. BMJ, 344, e1454.

Hu, F. B., van Dam, R. M., \& Liu, S. (2001). Diet and riskof type II diabetes: the role of types of fat and carbohydrate. Diabetologia, 44, 805-817.

Kennedy, L., Bittel, D. C., Kibiryeva, N., Kalra, S. P., Torto, R., \& Butler, M. G. (2006). Circulating adiponectin levels, body composition and obesity-related variables in Prader-Willi syndrome: comparison with obese subjects. International Journal of Obesity, 30, 382-387.

Khosravi-Boroujeni, H., Sarrafzadegan, N., Mohammadifard, N., Sajjadi, F., Maghroun, M., Asgari, S., et al. (2013). White rice consumption and CVD risk factors among Iranian population. Journal of Health, Population, and Nutrition, 31(2), 252.

Knowler, W. C., Barrett-Connor, E., Fowler, S. E., Hamman, R. F., Lachin, J. M., Walker, E. A., et al. (2002). Reduction in the incidence of type 2 diabetes with lifestyle intervention ormetformin. The New England Journal of Medicine, 346, 393-403.

L'Allemand, D., Eiholzer, U., Schlumpf, M., Torresani, T., \& Girard, J. (2003). Carbohydrate metabolism is not impaired after 3 years of growth hormone therapy in children with Prader-Willi syndrome. Hormone Research, 59, 239-248.

Lindmark, M., Trygg, K., Giltvedt, K., \& Kolset, S. O. (2010). Nutritient intake of young children with Prader-Willi syndrome. Food \& Nutrition Research, 54, 1-6.

Manson, J., \& Spelsberg, A. (1993). Primary prevention of non-insulin-dependent diabetes mellitus. American Journal of Preventive Medicine, 10(3), 172-184.

McCandless, S. E., \& Committee on Genetics (2011). Clinical report health supervision for children with Prader-Willi syndrome. Pediatrics, 127, 195-204.

Miller, J. L., Lynn, C. H., Driscoll, D. C., Goldstone, A. P., Shuster, J., Gold, J. A., et al. (2011). Nutritional phases in Prader-Willi syndrome. American Journal of Medical Genetics. Part A, 155, 1040-1049.

Miller, J. L., Lynn, C. H., Shuster, J., \& Driscoll, D. J. (2011). Carnitine and coenzyme Q10 levels in individuals with Prader-Willi syndrome. American Journal of Medical Genetics. Part A, 155A, 569-573.

Miller, J. L., Lynn, C. H., Shuster, J., \& Driscoll, D. J. (2013). A reduced-energy intake, well-balanced diet improves weight control in children with Prader-Willi syndrome. Journal of Human Nutrition and Dietetics, 26(1), 2-9.

Mizoue, T., Yamaji, T., Tabata, S., Yamaguchi, K., Ogawa, S., Mineshita, M., et al. (2006). Dietary patterns and glucose tolerance abnormalities in Japanese men. The Journal of Nutrition, 136(5), 1352-1358.

Nanri, A., Mizoue, T., Noda, M., Takahashi, Y., Kato, M., Inoue, M., et al. (2010). Rice intake and type 2 diabetes in Japanese men and women: the Japan Public Health Center-based Prospective Study. The American Journal of Clinical Nutrition, 92(6), 1468-1477.

Nicholls, R. D., \& Knepper, J. L. (2001). Genome organization, function, and imprinting in Prader-Willi and Angelman syndromes. Annual Review of Genomics and Human Genetics, 2, 153-175.

Nordmann, A. J., Nordmann, A., Briel, M., Keller, U., Yancy Jr., W. S., Brehm, B. J., et al. (2006). Effects of low-carbohydrate vs low-fat diets on weight loss and cardiovascular risk factors. Archives of Internal Medicine, 166, 285-293.
Oba, S., Nanri, A., Kurotani, K., Goto, A., Kato, M., Mizoue, T., et al. (2013). Dietary glycemic index, glycemic load and incidence of type 2 diabetes in Japanese men and women: the Japan Public Health Center-based Prospective Study. Nutrition Journal, 12(1), 165

Sakurai, M., Nakamura, K., Miura, K., Takamura, T., Yoshita, K., Nagasawa, S. Y., et al. (2016). Dietary carbohydrate intake, presence of obesity and the incident risk of type 2 diabetes in Japanese men. Journal of Diabetes Investigation 7(3), 343-351.

Salmeron, J., Ascherio, A., Rimm, E. B., Colditz, G. A., Spiegelman, D., Jenkins, D. J., et al. (1997). Dietary fiber, glycemic load, and risk of NIDDM in men. Diabetes Care, 20(4), 545-550.

Salmeron, J., Manson, J. E., Stampfer, M. J., Colditz, G. A., Wing, A. L., \& Willett, W. C. (1997). Dietary fiber, glycemic load, and risk of non-insulin-dependent diabetes mellitus in women. JAMA, 277(6), 472-477.

Sinha, R., Fisch, G., Teague, B., Tamborlane, W. V., Banyas, B., Allen, K., et al. (2002). Prevalence of impaired glucose tolerance among children and adolescents with marked obesity. The New England Journal of Medicine, 346, 802-810.

Song, Y. Y., Gong, R. R., Zhang, R. R., Zhang, Z., Li, Y. H., Hu, M. S., et al. (2012). Effects of a low-fat and high-carbohydrate diet on the physiological and biochemical indices in healthy youth with different body mass index. Sichuan da xuexuebao Yi xueban, 43, 9-14.

Sun, Q., Spiegelman, D., van Dam, R. M., Holmes, M. D., Malik, V. S., Willett, W. C., et al. (2010). White rice, brown rice, and risk of type 2 diabetes in US men and women. Archives of Internal Medicine, 170(11), 961-969.

Villegas, R., Liu, S., Gao, Y. T., Yang, G., Li, H., Zheng, W., et al. (2007). Prospective study of dietary carbohydrates, glycemic index, glycemic load, and incidence of type 2 diabetes mellitus in middle-aged Chinese women. Archives of Internal Medicine, 167(21), 2310-2316.

Wabitsch, M., Hauner, H., Hertrampf, M., Muche, R., Hay, B., Mayer, H., et al. (2004). Type II diabetes mellitus and impaired glucose regulation in Caucasian children and adolescents with obesity living in Germany. International Journal of Obesity and Related Metabolic Disorders, 28, 307-313.

Yang, A., Jinsup, K., Sung Yoon, C., \& Dong-Kyu, J. (2017). Prevalence and risk factors for type 2 diabetes mellitus with Prader-Willi syndrome: a single center experience. Orphanet Journal of Rare Diseases, 12, 146.

\section{Submit your manuscript to a SpringerOpen ${ }^{\circ}$ journal and benefit from:}

- Convenient online submission

Rigorous peer review

- Open access: articles freely available online

High visibility within the field

- Retaining the copyright to your article

Submit your next manuscript at $>$ springeropen.com 